16. Gaps and Needs Analysis: European Report and Roadmap (2016), ISBN 978-972-674-778-9, https://repositorioaberto.uab.pt/handle/10400.2/5980 (Accessed 5 August 2020).

17. R. K. Moloo, K. K. Khedo, T. V. Prabhakar. Critical evaluation of existing audio learning systems using a proposed TOL model. Computers and Education, 117 (2018), pp. 102-115, doi.org/10.1016/j.compedu.2017.10.004

18. L. Lin, P. Ginns, T. Wang, P. Zhang. Using a pedagogical agent to deliver conversational style instruction: What benefits you can obtain? Computers and Education, 143 (2020), pp. 1-9, doi.org/10.1016/j.compedu.2019.103658

19. M. Lewis, J. Hill. Practical techniques for language teaching. 4th ed. Hove, England. Language Teaching Publications (1992), pp. 136.

20. G. Kapperman, E. Koster, R. Burman. The study of foreign languages by students who are blind using the JAWS screen reader and a refreshable Braille display. Journal of Visual Impairment and Blindness, vol. 112, issue 3 (2018), pp. 317-323, $10.1177 / 0145482 \times 1811200312$

21. T. Belova. Accessible language: Foreign language teaching strategies for blind and visually impaired students. Advances in Social Science, Education and Humanities Research, vol. 144 (2017), pp. 592-596, http://atlantis-press.com/proceedings/ icadce-17/25881385 (Accessed 19 August 2020).

DOI 10.15826/B978-5-7996-3081-2.14

\title{
Assessment Cultures and Virtual L2 Teaching and Learning
}

\author{
Leontjev Dmitri', Rasskazova Tatiana ${ }^{2}$ \\ ${ }^{1}$ University of Jyväskylä, Jyväskylä, Finland \\ 2 Ural Federal University, Ekaterinburg, Russia; \\ University of Jyväskylä, Jyväskylä, Finland \\ Corresponding author:Tatiana Rassakazova, trasska@mail.ru
}

Abstract. The unprecedented emergency remote teaching [Hodges et al., 2020] has created unique challenges, with educators facing higher demands placed on them as they have to assure quality teaching, learning, and assessment 
under the constraints of time and additional commitments in their professional and personal lives. In this paper, we discuss how existing understandings and conceptualisations, applicable to both online and traditional classrooms, can guide educators in overcoming these challenges and, indeed, in understanding what online modality affords in learner assessment. Conceptually, we will above all, base our paper on the notion of assessment culture, namely assessment of learning and assessment for (AfL) learning cultures [Davison \& Leung, 2009], arguing for the benefit of the latter in the classroom. We will also draw upon the notion of higher order and lower order thinking skills [Anderson, Brunfaut, \& Harding, 2001], eliciting language functions rather than linguistic, grammatical, and syntactic categories as the object of assessment. We will base our discussion on a number of recently completed and ongoing studies in several L2 (second or foreign language) contexts. We will discuss how assessment cultures and language functions externalising thinking processes can inform educators' assessment practices, alleviating educators' concerns for reliability in inferences made from learners' performance on online assessments and learner engagement.

Keywords: classroom-based assessment, assessment cultures, emergency remote teaching, LOTS and HOTS

\section{Introduction}

With the novel COVID-19 pandemic, the world is facing challenges that are unprecedented in modern times. This is true for education as well [Abdul Rahim, 2020]. While institutions may possess tools for, and models of, online instruction, Hodges et al. (2020) warn against likening the swift shift to the online modality of teaching and learning happening in response to the public health emergency with well-planned learning experiences. They propose the term 'emergency remote teaching' (ERT) to refer to this: "a temporary shift of instructional delivery to an alternate delivery mode due to crisis circumstances." The main rationale for this term, given by Hodges et al. (2020), was to differentiate between the current situation and traditional online teaching (learning, instruction, or any other such term), the latter presupposing careful instructional design and planning. This is not to say, however, that principles and models of successful online education as well as the body of research on it should be disregarded when searching for reliable solutions for challenges emerging with the shift to ERT. The same holds true for the concepts, solutions, models, and frameworks coming from face-toface education informing ERT. 
In this paper, we would like to focus on assessment in ERT (and online learning alike), offering some, though by no means comprehensive, vision of what assessment in ERT can be. We should note that we are not aiming at a comprehensive discussion of taxonomies and ecologies of online learning with the goal of outlining how these can inform ERT. We refer the reader to excellent works on online learning by Cope and Kalantzis (2017) and Means, Bakia, and Murphy (2014). The reason for us focusing on namely assessment in ERT stems from concerns brought or intensified with transitioning to ERT with regard to learner anxiety and engagement, reliability concerns, and equity threats [e.g., Gao, 2020; Gares, Kariuki, \& Rempel, 2020; Osman, 2020; Whittle, Tiwari, Yan, \& Williams, 2020]. In the paper, we will base our discussion on the notions of assessment cultures and higher-order thinking skills, building on several studies, both completed and ongoing, conducted in various L2 (second/foreign language) education contexts. In the two sections to follow, we will outline the theoretical basis for our discussion.

\section{Assessment culture and ERT}

The current understanding of classroom assessment and learning is that they are intrinsically linked [Alderson, Brunfaut, \& Harding, 2017]. The way this link is made, though, depends on how the role of assessment is perceived: as a measurement of learning outcomes or as a way to promote learning. The first rests on the positivist paradigm, concerned with learners demonstrating the outcomes of their learning, issues of reliability and equality, and emphasising the product of learning. The second, placed within the socio-constructivist paradigm, is concerned with the question of how assessment should promote learning, rather than measuring it, the process of learning and equity being forefronted [see Lam, 2016]. On the level of function of separate assessment activities, these two views have been realised as summative and formative assessments respectively.

With regard to ERT, it has indeed been found and proposed in ERT guidelines that formative assessment and feedback (or a balance between formative and summative assessment) should decrease anxiety, increase student engagement, and indeed, guide learning [Gao, 2020; Abdul Rahim, 2020]. However, it remains a challenge for educators to understand differences between formative and summative assessments and more importantly implement formative assessments in their practices alongside summative 
assessments [Black \& Wiliam, 2018; Hopfenbeck, 2018]. This challenge is exacerbated in the ERT context [Gao, 2020].

Outside the ERT context but, in our view relevant to it, a suggestion which has been proposed by the first author elsewhere [Leontjev \& deBoer, 2020b], is to go beyond the function of individual assessments in the classroom towards thinking about the purpose of classroom-based assessment and linking it to the larger context of assessment culture. Davison and Leung (2009) provide an excellent discussion of 'assessment as culture' based on Davison' (2008) model of teacher-based assessment (see Figure 1). Davison and Leung (2009) bring forth fundamental differences between the two cultures of assessment, assessment of learning and assessment for learning culture. Whereas in the former, Davison and Leung (2009) argued, the roles of the teacher and the assessor in the classroom are clearly demarcated, and so is the role of summative and formative assessment, in the latter, regardless of the form (i. e., a test), assessment should above all promote learning, i.e. above all, have a formative function, the teacher's and the assessor's role being one and the same. Leontjev and deBoer (2020b) further argue that the considerations of assessment culture should go beyond the educational policy and place the classroom assessment practices within the wider context of beliefs, ideologies, and educational histories [see also Black \& Wiliam, 2018]. This, we argue, elicits the complex nature of how classroom assessment culture comes into being as a result of complex interactions at various levels - individual, classroom, institutional, and societal - becoming the more so relevant in the ERT context. A change in classroom assessment from of learning to for learning, which operationalised above all, as a shift from assessing the product of learning to that of the learning process, requires taking these factors into account.

Davison's (2008) model can be useful in informing this shift, as it visualises the process as a cycle of interconnected changes, moving the focus from individual assessment events to a continuity in teaching, learning, and assessment.

Briefly, the model places assessment activities within the cycle of interconnected phases of planning, and implementing assessments, making inferences, each of the phases informed by the previous, adjustments made to teaching, learning, and the following assessment if needed. Furthermore, the phases in the following cycles, as argued by Leontjev and deBoer (2020a) should not only be informed by the immediately preceding cycles, but by all of the assessment cycles. We will later in this paper discuss with reference to Leontjev and deBoer (2020b) how, informed by this understanding, as- 


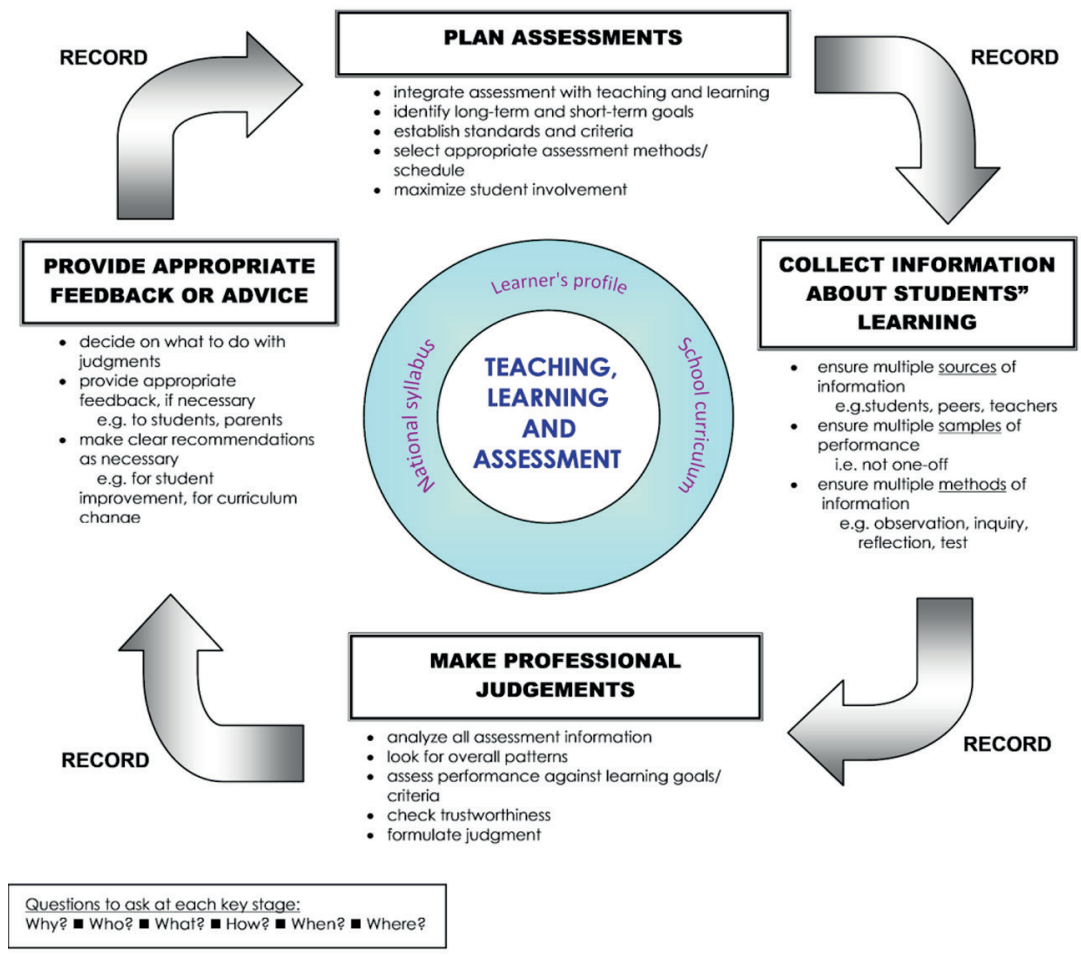

Figure 1. Teacher-based assessment cycle [Davison, 2008]

sessment happening during a course can lead to and inform the assessment of the 'product of learning'. Assessment of the process informing assessment of the product of learning, we will argue, can alleviate the reliability concerns intensifying with the shift to ERT. We will also, describing our ongoing study of educators' and learners' experiences with the ERT, discuss the importance of learners' beliefs about expectations of assessment, placing thus the discussion more strongly within the notion of assessment culture.

\section{From language to its functions:}

\section{higher-order thinking skills in ERT assessment}

At its core, the role of educational assessment is to elicit and externalise learners' cognitive skills. Learning as a cognitive event is not observable directly, so, as Dalton-Puffer [2013,220] stated, "the nearest we can hope to get 
is its observable analogues." The first conceptualisation, that comes to mind with regard to externalisation of learners' cognitive processes, is clearly Bloom's Taxonomy [Bloom et al., 1956] including its more recent developments [Anderson et al., 2001; Heer, 2012], which conceptualises thinking skills as learning objectives of increasing cognitive demands, ranging from remembering at the lower end of the scale (lower-order thinking skills; LOTS) to creating at its higher end (higher-order thinking skills). The cognitive dimension is further enhanced by the knowledge dimension, ranging from factual knowledge at the lower end of the scale to metacognitive knowledge at its higher end [Heer, 2012].

The applications of this thinking are numerous, the performative verbs representing these cognitive and knowledge processes, embedded in numerous curricula throughout the world and in impactful tools for teaching, learning, and assessing languages such as the Common European Framework of Reference [CEFR; CoE, 2018], in the form of can-do statements. There have also been developments such as that on the construct of cognitive discourse functions [CDFs; Dalton-Puffer, 2013] for conceptualising learner academic proficiency as integration of content knowledge and linguistic knowledge. Dalton-Puffer (2013) argued against the essentialist thinking behind the hierarchical positioning of thinking skills / learning objectives and we recognise the value of Dalton-Puffer's stance, particularly that which concerns the ongoing assessment promoting learning in centrifugal processes and their products (e.g., interaction with learners in the classroom or learners creating a text). However, particularly as far as learning objectives and their elicitation in assessment are concerned, such thinking becomes indispensable [Phakiti, 2018].

Assessments, particularly assessments of learning outcomes, are easier to design as they often elicit LOTs, and these lend themselves more readily to be elicited in task types, such as multiple-choice, easier to score objectively and easier to implement online. However, with the ERT shift, these are also a source of concern for academic integrity, learner cheating and plagiarism, and especially what regards written exams [e.g., Gares et al., 2020]. The authors did not elaborate on the way these exams were designed. However, considering the authors' questioning whether students presenting their own work or not being an issue, the exams might have targeted LOTs, or, perhaps there was a combination of factors, including lack of online proctoring, plagiarism detection, lack of systematic information about students' learning, 
as well as, taking into account the high-stakes nature of written examinations, learners' desire to excel in demonstrating the learning outcomes beyond their actual ability (or the instructors' beliefs of that being the case, or both).

It certainly is important not to interpret any phenomenon in a limited way, with reference to but one factor. Still, for the benefit of the argument in this paper, we will in the following two sections, outline a number of our ongoing and completed studies relevant for improving L2 assessment in ERT from two perspectives: assessment cultures and language functions with the focus on HOTs. As these studies have been either reported or in the process of reporting elsewhere or works in progress and considering the lack of space, we will not give a full account of these studies, but provide, hopefully sufficient detail for building our argument and helping the reader to follow it.

\section{Assessment cultures in online assessment: teachers' and learners' views and successful implementations}

The first study we wish to outline in this section is our collaborative work in progress in which we embarked in observing two teacher-training courses, one being an example of ERT (CELTA) and the other, an example of what Hodges et al. (2020) refer to as well planned, prepared, and developed (EMI). Both courses were designed and developed by Cambridge Assessment English. Both courses had ended by the time we started writing this paper. We are now in the process of collecting the experiences of learner-participants and the instructors on the courses. Hence the present outline is based on incomplete data. We plan to report on the findings once the full data set has been collected and analysed. The second author was also the instructor on the CELTA course in the study. The two courses are summarised in the following Table 1.

To add to Table 1, the two courses are similar in that (a) both are designed for professional development of English language teachers, (b) both are conducted fully online, (c) trainees have to go through a selection procedure, (d) the selection process was based on the trainees' level of language proficiency, and (e) both focus on written assignments. The difference between them is that the CELTA course should, based on Hodges et al. (2020) be classified as ERT. It appeared in March-April 2020 as a response to the novel coronavirus pandemic, as the lockdown caught centres delivering the courses off-guard and they had to cope with the situation and finish the courses. The other course, EMI (English as a Medium of Instruction), had existed 
in a completely online mode for several years before the pandemic situation, and was a well-designed, carefully planned course. It was concluded that no modifications were required for this latter course, so it continued as planned. CELTA trainees chose the online modality voluntarily, coming

Table 1

The Certificate in English Language Teaching to Adults and English as a Medium of Instruction teacher-training courses in the study.

\begin{tabular}{|c|c|c|}
\hline & $\begin{array}{l}\text { CELTA (Certificate } \\
\text { in English Language } \\
\text { Teaching to Adults) }\end{array}$ & $\begin{array}{l}\text { EMI (English as a Medium } \\
\text { of Instruction) }\end{array}$ \\
\hline Modality & Fully online & Fully online \\
\hline $\begin{array}{l}\text { Instructor role } \\
\text { online }\end{array}$ & Active instruction online & None \\
\hline Pacing & $\begin{array}{l}\text { Class-paced with some } \\
\text { self-paced (duration - } \\
5 \text { weeks) }\end{array}$ & $\begin{array}{l}\text { Self-paced (open entry, open } \\
\text { exit) within certain time limit } \\
\text { (duration }-4 \text { weeks) }\end{array}$ \\
\hline $\begin{array}{l}\text { Student Role } \\
\text { Online }\end{array}$ & $\begin{array}{l}\text { - Collaborate with peers } \\
\text { - Complete problems or } \\
\text { answer questions } \\
\text { - Explore simulation and } \\
\text { resources }\end{array}$ & $\begin{array}{l}\text { - Listen or read } \\
\text { - Complete problems or } \\
\text { answer questions } \\
\text { - Explore simulation and } \\
\text { resources }\end{array}$ \\
\hline $\begin{array}{l}\text { Online Communi- } \\
\text { cation Synchrony }\end{array}$ & $\begin{array}{l}\text { A blend of synchronous } \\
\text { and asynchronous }\end{array}$ & Asynchronous only \\
\hline Source of Feedback & $\begin{array}{l}\text { - Automated } \\
\text { - Teacher } \\
\text { - Peers }\end{array}$ & $\begin{array}{l}\text { - Automated } \\
\text { - Teacher }\end{array}$ \\
\hline $\begin{array}{l}\text { Role of Online } \\
\text { Assessments }\end{array}$ & $\begin{array}{l}\text { - Determine if student } \\
\text { is ready for new content } \\
\text { - Provide student or } \\
\text { teacher with informa- } \\
\text { tion about learning state } \\
\text { - Input to grade } \\
\text { - Identify students } \\
\text { at risk of failure }\end{array}$ & $\begin{array}{l}\text { - Provide student or teacher } \\
\text { with information about learn- } \\
\text { ing state } \\
\text { - Feedback to grade } \\
\text { - Identify students at risk } \\
\text { of failure }\end{array}$ \\
\hline Motivation & $\begin{array}{l}\text { Mainly intrinsic } \\
\text { (trainees enrolled on } \\
\text { the course voluntarily) }\end{array}$ & $\begin{array}{l}\text { Mainly extrinsic (the require- } \\
\text { ment of the University) }\end{array}$ \\
\hline
\end{tabular}


from different backgrounds and teaching contexts, with or without prior teaching experience. All of the learner-participants self-funded their studies. The EMI trainees were part of a grant-funded project, coming from the same university context.

An interesting difference between the two courses emerged with reference to academic integrity. In the CELTA course, the amount of resubmissions based on 'lacking the academic integrity criterion' was minimal. Meanwhile, the EMI instructor oftentimes questioned the independent nature of the learners' submitted assignments, noting the verisimilitude of these among several learners. We suggest that the issue can be discussed with reference to assessment culture, the institutional constraints and institutionalised struggles. On the more macro level, assessment culture is a result of tradition, beliefs, and ideologies [see Leontjev \& deBoer, 2020b], which explains the concerns for academic integrity by the instructors in both courses. Even if not adhering to the assessment of learning culture, the instructors, we assume, could recognise the learner participants' desire to demonstrate their successfulness in learning outcomes, which could override their desire to develop. Whether there was indeed an issue with the academic integrity or whether this was the interpretation by the instructors remains to be seen. However, what is clear is that the institution requiring their academic staff to participate in the course played its role in that apparent difference between the two courses. We are not going to investigate further whether the learners indeed copied their work from one another for ethical reasons; we note only that the academic integrity concerns emerged not as the result of the study, as we did not direct the EMI instructor to voice this concern. Still we plan to explore it further with the instructor of the CELTA course as to how assessment culture and institutional structures might have impacted on her interpretations. To elaborate, in the EMI group, the institutionalised struggles introduced by the top-down requirement of the course participation could have increased the participants' anxiety and the (perceived) expectation to succeed on the course. This, combined with the perception of the course being extra work on top of other commitments, could have resulted in the trainees resorting to copying the assignments from their peers. Alternatively, the instructor's recognition of the role of the institutional structures and power relations involved in the EMI course could have led to the instructor interpreting some trainees' work as lacking o academic integrity also in cases where the verisimilitude of their work stemmed from 
the learning materials and lectures, the trainees appropriating others' words in their work. Regardless of the interpretation, we note that assessment culture in specific courses is a complex phenomenon resulting from the interaction of various factors on micro, meso, and macro levels.

Based on these preliminary observations, the following issues should be considered: (1) motivation of taking courses during the ERT times; and (2) assessments eliciting HOTs (to eliminate doubts on 'academic integrity'). With regard to this latter point, in the following section, we outline an early work in progress which is currently in the design stage emerging as a follow-up to the study we discussed so far. We next give a brief outline of one study informed by Davison and Leung's (2009) discussion of AfL culture and assessment cycle which can offer a way of minimising the academic integrity concerns which emerged in the EMI course in this study.

The first author and his colleague [Leontjev \& deBoer, 2020a] have recently reported, building on Davison's (2008) model of assessment cycle, on how assessing the process of learners working towards the final product can meaningfully inform the assessment of this product. Namely, the authors demonstrated that even when learners use somebody else's words in their performance, it can be discerned whether there is understanding behind the words learners used.

To elaborate, the study was conducted in the context of an L2 English course in a Japanese university, where the learner participants were L1 Japanese undergraduate students of engineering or agriculture, their English proficiency being roughly at level A2 on the CEFR scale. The instructor, the second author, designed an activity where the learners, having watched an unadapted video on a phenomenon (Earth breathing in the case of the group whose performance the authors analysed), were requested to work in an online forum, first building their understanding of this phenomenon and then creating a presentation for their peers and the instructor. The authors traced how "the learners developed their conceptual understanding and were able to present it in academic English; despite the fact that in the beginning, they were given language and a concept beyond their unassisted level of performance to discuss" [Leontjev \& deBoer, 2020a]. In other words, having at the outset the language that the speaker in the video used, which the learners did not fully understand, and a phenomenon the learners did not have a full conceptual understanding of, the learners using both as a resource and relying 
on their histories brought into the interaction, gradually co-constructed the understanding of both.

Hence, when a learner used the speaker's words in their final presentation, the teacher could be reasonably sure that the learner used this language with understanding. We note that the instructor never intervened in the learners online asynchronous interaction, using it rather as a history of the whole process, which, then, in the following assessment cycle, informed the teacher's assessment of the learners' presentations. The online environment of the study was, therefore, not an obstacle for assessment but an affordance, both developing the learners' understanding and their use of academic language and informing the teacher's assessment.

The cyclic model of classroom teaching, learning and assessment can, therefore, be used to inform ERT. Online modality offers ample opportunities for documenting the learning process, which can be used to make adjustments to teaching and learning in the following cycles and to inform the understanding of the product of learning, thus alleviating reliability concerns.

\section{Language functions informing learner assessment}

As we discussed in the previous section, there is a follow-up study being designed at the moment based on the emerging result of our study of a CELTA and an EMI course which we outlined in the previous section. The study is informed by Davison and Leung's (2009) assessment cycle, the argument by Leontjev and deBoer (2020a) for assessment of the process informing the teacher's assessment of learning outcomes, as well as the notion of higher-order thinking skills. A tool we suggest to inform classroom assessment and learning is a guided self-reflection (i. e. self-assessment). The learners will be asked to reflect on their learning process during the course with reference to particular examples from their own and their colleagues' learning experiences on the course. The participants' reflection will be guided by the performative verbs reflecting higher-order thinking skills. These verbs will be a part of the prompts used as a part of the instruction to the participants' self-reflection, e.g., 'think how you can integrate what you have learned in this session with your prior knowledge and professional experience' (analysing on the procedural level of knowledge), 'propose how you can use the techniques we covered in your teaching' (applying on the metacognitive level), or 'which of your own biases can you deconstruct using theory $\mathrm{X}$ as a critical lens and how' (analysing on the metacognitive level) [see Heer, 
2012]. Recognising that these are learning objectives rather than learning activities, alongside the instrument, we will design and modify activities leading to these reflections. We, nevertheless, based on Dalton-Puffer's (2013) argument, suggest that guiding the function of the participants' reflection in this way will elicit both the teacher-trainees' higher-order thinking skills and help them mobilise their linguistic resources required for externalising their thinking.

We envision several benefits of this recurring activity. First and foremost, we suggest this will further guide the participants' learning process. Furthermore, this will serve as assessment for learning, stretching across assessment cycles and allowing for making adjustments in teaching when needed. Finally, this will make the writing process highly individual, reducing the possibility of the participants reproducing others' words in their work. This latter will, therefore, also give the course instructor confidence that there is an understanding behind the participants' words when the participants repeat the words of others [see Leontjev \& deBoer, 2020a]. We plan to recruit one instructor and teacher participants in an EMI course, collecting qualitative data from the learners' reflections and three interviews with the instructor (at the outset, in the middle, and after the course will have finished) as well as the instructor's reflections throughout the course to trace how the instructor's understanding of the trainee's learning process changes and how the trainees develop throughout the course.

The second study we would like to give an outline of in this section is another work-in-progress conducted by the first author and several of his colleagues [deBoer, Leontjev, \& Friederich, submitted]. The study grew out of the desire of the third author, who was an instructor in an academic writing course to develop the assessment rubric from being a tool for grading to being a tool for self-, peer-, and teacher-based assessment whose goal is development. Conceptually, the study is positioned within the Action-oriented Approach [AoA; Piccardo \& North, 2019] and is strongly informed by Dalton-Puffer's (2013) construct of cognitive discourse functions, which, as we briefly mentioned above, is a non-hierarchical list of performative verbs which both serve as an externalisation of thinking processes and communicative intentions. The Action-oriented approach, in turn, conceptualises development not as a linear but as a complex process of learners mobilising different competences and resources in unique ways in unique contexts. Hence, learner reflection and agency are preconditions for development, 
the teacher's goal being creating conditions for learners to mobilise their resources. The tasks in AoA should not be a mock-up of the potential future but should be meaningful in the here and now, learning objectives being authentic and meaningful. The purpose of assessment becomes then to collect information to help learners to reach these objectives.

The first step in the rubric development was analysing the functions of the text the learners were required to write - introductory sections of an academic report leading to research questions. From there, the authors worked backwards, suggesting which functions were the prerequisite for these, gradually working backwards in terms of quality of the argument in learner papers. The following step was making sure that learner agency and reflection were elicited at every step, but guidance with regard to how the learners could improve their text was included at every step.

The outcome was a scale which included statements such as "I have identified the facts surrounding my research and now I need to identify how these facts support arguments people are making about my topic" at its lower end to statements such as "I have presented all the arguments in a coherent manner and identified several complex perspectives and gaps ... Now I need to provide a link between the arguments..." The scale also contains a space for the learner's elaboration, asking how they are going to improve the text for it to include the functions as advised in the rubric.

The rubric, therefore, (a) focuses on the learner, as the main agent in assessment, (b) elicits the process of developing writing rather than issues in the text at hand, and (c) leaves it up to the learner to mobilise their linguistic resources to improve their text such that it expresses the specific functions enabling also learner reflection by explicitly asking them to report how they are going to improve their texts. This reflection together with the changes in the learner's text provides valuable information to the teacher which can then be used to give further feedback to learners and make adjustments in the teaching. Furthermore, this information can inform the teacher's final evaluation of the learners' work, or, indeed, change it, as the teacher shifts focus from accuracy to how successful the learners are in building their argument.

There has only been only some preliminary work so far with regard to exploring learners' experiences in using the rubric, but the results suggest that learners use the rubric to develop their texts in their unique ways, which is exactly what the goal of the rubric is. 


\section{Discussion and Conclusion}

As we elaborated at the outset of the paper, we, focusing on some issues raised in recently published works on Emergency Remote Teaching [see Hodges et al., 2020], discussed how some existing concepts - assessment cultures, higher-order thinking skills, and cognitive discourse functions both deepen the understanding of these issues and guide us towards finding solutions to them in the time of ERT. We based our discussion on both completed and on-going studies we have completed, are conducting, or are in the process of designing.

To repeat, the first on-going study is about two professional development courses for teachers of EFL (CELTA \& EMI), both courses designed and delivered by Cambridge Assessment English. Our qualitative analysis of the currently populated data set informed by the notion of assessment cultures suggests that the learning process is also shaped by factors other than the nine dimensions, mentioned by Hodges et al. (2020), depending on motivation and the desire to grow professionally, as well as is constrained by institutional structures and struggles, all of these factors intertwined.

The second study [Leontjev \& deBoer, 2020a] we outlined in this paper explored how the teacher's assessment of the learning outcomes can be meaningfully informed by the assessment of the learning process, as learners co-construct meanings in asynchronous interaction. The study furthermore illustrated the benefit of the online modality, capitalising on the affordances of recording the process of the learning as externalised by learners' posts in an online forum, the teacher having access to the whole of this process.

The third study is how the learning process of academic writing and its assessment by the learners and the teacher can be meaningfully guided by the notion of CDFs. The study discussed how shifting the focus of an assessment rubric from academic language to the functions of learner writing can both develop the learners' understanding of the writing process and yield important insights into writing for the teacher, as learners mobilise their linguistic resources in their unique ways to express the functions of academic papers.

We also briefly introduced a study which is currently being designed, informed by the notion of higher-order thinking skills, whose goal is to (a) minimise issues with (perceived) academic integrity, (b) inform the instructor's assessment of their learners, and (c) further guide the learning process in the course. 
Online learning and teaching require much effort on the side of the educators and instructors. This is exacerbated by the further challenges that ERT brings with it. Admittedly, but perhaps, understandably, we have not given any one-size-fits-all solution to the challenges we outlined. However, we hope that the applications of the concepts of AfL, HOTS, and CDFs to change assessment and teaching activities and practices that we outlined in the paper can inspire creative solutions to the challenges of the ERT time. This latter, of course, does not mean that these solutions should not be wellplanned, designed, and tested, as the learners' success depends on how well educators face these challenges.

\section{Conflict of Interest}

The authors have no conflict of interest to declare.

\section{Acknowledgments}

A study outlined in this paper is supported by the Russian Foundation for Basic Research (Grant No. 17-29-09136/20 "Multilingualism in the era of post-literacy: Philosophical and cultural studies and methodological and pedagogical development of a multilingual education model").

\section{References:}

1. A. F. Abdul Rahim. Guidelines for Online Assessment in Emergency Remote Teaching during the COVID-19 Pandemic. Education in Medicine Journal, 12(2) (2020), pp. 59-68. https://doi.org/10.21315/eimj2020.12.2.6

2. J.C. Alderson, T. Brunfaut, L. Harding. Bridging assessment and learning: a view from second and foreign language assessment. Assessment in Education: Principles, Policy \& Practice, 24(3) (2017), pp. 379-387. https://doi.org/10.1080/0 969594X.2017.1331201

3. L. W. Anderson (Ed.), D. R. Krathwohl (Ed.), P.W. Airasian, K. A. Cruikshank, R.E. Mayer, P.R. Pintrich, J. Raths, M.C. Wittrock. A taxonomy for learning, teaching, and assessing: A revision of Bloom's Taxonomy of Educational Objectives (Complete edition). Longman, New York (2001).

4. B. S. Bloom (ed.). Taxonomy of educational objectives: Handbook 1, Cognitive domain. David McKay, New York (1956).

5. P. Black, D. Wiliam. Classroom assessment and pedagogy. Assessment in Education: Principles, Policy \& Practice, 25(6) (2018), pp. 551-575. https://doi.org/10. 1080/0969594X.2018.1441807 
6. B. Cope, M. Kalantzis. E-Learning Ecologies: Principles for New Learning and Assessment. Routledge, New York (2017).

7. Council of Europe. (2018). Common European Framework of References for Languages: Learning, Teaching, Assessment. Companion Volume with New Descriptors. Provisional Edition. Language Policy Programme. Education Policy Division. Education Department. www.coe.int/lang-cefr

8. C. Dalton-Puffer. A construct of cognitive discourse functions for conceptualising content-language integration in CLIL and multilingual education. European Journal of Applied Linguistics, 1(2) (2013), pp. 216-253. https://doi.org/10.1515/ eujal-2013-0011

9. C. Davison. Assessment for learning: Building inquiry-oriented assessment communities. Paper presented at Annual TESOL Convention, International TESOL, New York (March 2008).

10. C. Davison, C. Leung. Current Issues in English Language Teacher-Based Assessment. TESOL Quarterly, 43(3) (2009), pp. 393-415. https://doi. org/10.1002/j.1545-7249.2009.tb00242.x

11. M. deBoer, D. Leontjev, L. Friederich (submitted). From language to function: Developing assessment rubrics.

12. X. Gao. Australian Students' Perceptions of the Challenges and Strategies for Learning Chinese Characters in Emergency Online Teaching. International Journal of Chinese Language Teaching, 1(1) (2020), p. 83. https://doi.org/10.46451/ ijclt.2020.06.04

13. S. L. Gares, J. K. Kariuki, B. P. Rempel. Community Matters: Student-Instructor Relationships Foster Student Motivation and Engagement in an Emergency Remote Teaching Environment. Journal of Chemical Education (2020), doi. org/10.1021/acs.jchemed.0c00635

14. R. Heer. A model of learning objectives — based on A taxonomy for learning, teaching, and assessing: a revision of Bloom's taxonomy of educational objectives. Center for Excellence in Learning and Teaching, Iowa State University (2012).

15. C. Hodges, S. Moore, B. Lockee, T. Trust, A. Bond. The difference between emergency remote teaching and online learning. Educause Review (2020). https:// er.educause.edu/articles/2020/3/the-difference-between-emergency-remote-teaching-and-online-learning

16. T. Hopfenbeck. Classroom assessment, pedagogy and learning — twenty years after Black and Wiliam 1998. Assessment in Education: Principles, Policy \& Practice, 25(6) (2018), pp. 545-550. https://doi.org/10.1080/0969594X.2018.1553695 
17. R. Lam. Assessment as learning: examining a cycle of teaching, learning, and assessment of writing in the portfolio-based classroom. Studies in Higher Education, 41(11) (2016), pp. 1900-1917. https://doi.org/10.1080/03075079.2014.999317

18. D. Leontjev, M. deBoer. Multimodal mediational means in assessment of processes: an argument for a hard-CLIL approach. International Journal of Bilingual Education and Bilingualism (2020a), https://doi.org/10.1080/13670050.2020.1754329

19. D. Leontjev, M. deBoer. Conceptualising assessment and learning in the CLIL context. An introduction. In DeBoer M. \& Leontjev D. (Eds.). Assessment and Learning in Content and Language Integrated Learning (CLIL) Classrooms: Approaches and Conceptualisations. Springer, Netherlands (2020b; forthcoming).

20. B. Means, M. Bakia, R. Murphy. Learning online: What research tells us about whether, when and how. Routledge (2014).

21. M.E. Osman. Global impact of COVID-19 on education systems: the emergency remote teaching at Sultan Qaboos University. Journal of Education for Teaching (2020), pp. 1-9, doi.org/10.1080/02607476.2020.1802583

22. A. Phakiti. Assessing Higher-Order Thinking Skills in Language Learning. In The TESOL Encyclopedia of English Language Teaching. John Wiley \& Sons, Inc., Hoboken, NJ (2018), pp. 1-7, doi.org/10.1002/9781118784235.eelt0380

23. E. Piccardo, B. North. The Action-oriented approach: A dynamic vision of language education. Multilingual Matters, Bristol, UK (2019).

24. C. Whittle, S. Tiwari, S. Yan, J. Williams. Emergency remote teaching environment: a conceptual framework for responsive online teaching in crises. Information and Learning Sciences, 121(5/6) (2020), pp. 311-319, doi.org/10.1108/ ILS-04-2020-0099 